\title{
A single nucleotide polymorphism in NEUROD1 is associated with production traits in Nelore beef cattle
}

\author{
P.S.N. de Oliveira ${ }^{1}$, P.C. Tizioto ${ }^{1}$, W. Malago Jr${ }^{1}$, M.L. do Nascimento ${ }^{2}$, \\ A.S.M. Cesar'2, W.J.S. Diniz ${ }^{3}$, M.M. de Souza ${ }^{3}$, D.P.D. Lanna ${ }^{2}$, R.R. Tullio ${ }^{1}$, \\ G.B. Mourão ${ }^{2}$, M. de A. Mudadu ${ }^{1}$, L.L. Coutinho² and L.C. de A. Regitano ${ }^{1}$ \\ ${ }^{1}$ Embrapa Pecuária Sudeste, São Carlos, SP, Brasil \\ ${ }^{2}$ Departamento de Zootecnia, Universidade de São Paulo, São Paulo, SP, Brasil \\ ${ }^{3}$ Departamento de Genética e Evolução, Universidade Federal de São Carlos, \\ São Carlos, SP, Brasil
}

Corresponding author: L.C. de A. Regitano

E-mail: luciana.regitano@embrapa.br

Genet. Mol. Res. 15 (2): gmr.15028161

Received November 27, 2015

Accepted January 29, 2016

Published July 15, 2016

DOI http://dx.doi.org/10.4238/gmr.15028161

\begin{abstract}
Feed efficiency and carcass characteristics are latemeasured traits. The detection of molecular markers associated with them can help breeding programs to select animals early in life, and to predict breeding values with high accuracy. The objective of this study was to identify polymorphisms in the functional and positional candidate gene NEUROD1 (neurogenic differentiation 1), and investigate their associations with production traits in reference families of Nelore cattle. A total of 585 steers were used, from 34 sires chosen to represent the variability of this breed. By sequencing 14 animals with extreme residual feed intake (RFI) values, seven single nucleotide polymorphisms (SNPs) in NEUROD1 were identified. The investigation of marker effects on the target traits RFI, backfat thickness (BFT), ribeye area (REA), average body weight (ABW), and metabolic body weight $(\mathrm{MBW})$ was performed with a mixed model
\end{abstract}


using the restricted maximum likelihood method. SNP1062, which changes cytosine for guanine, had no significant association with RFI or REA. However, we found an additive effect on ABW $(\mathrm{P} \leq 0.05)$ and MBW ( $\mathrm{P} \leq 0.05)$, with an estimated allele substitution effect of -1.59 and $-0.93 \mathrm{~kg}^{0.75}$, respectively. A dominant effect of this SNP for BFT was also found $(\mathrm{P} \leq 0.010)$. Our results are the first that identify NEUROD1 as a candidate that affects BFT, ABW, and MBW. Once confirmed, the inclusion of this SNP in dense panels may improve the accuracy of genomic selection for these traits in Nelore beef cattle as this SNP is not currently represented on SNP chips.

Key words: Bos indicus; Body composition; Candidate gene; Feed efficiency

\section{INTRODUCTION}

Brazil is an important global producer and exporter of beef. Among the beef cattle breeds used in the country, Nelore is the most popular due to its remarkable levels of production and its adaptability and resilience to tropical environments. Feed efficiency has a large effect on production costs; however, despite its moderate heritability, it has not been included in animal breeding programs, possibly for being a labor-intensive and late-measured phenotype. Selection for more efficient animals may result in reductions in pasture area and pollutant production, in addition to being more profitable for producers (Basarab et al., 2003). Backfat thickness (BFT) and ribeye area (REA) are important traits of late-measurement for the beef industry, and the investigation of molecular markers associated with these traits could lead to their inclusion in breeding programs.

NEUROD1 (Neurogenic differentiation 1) has been reported as a candidate gene for feed efficiency (Barendse et al., 2007). This gene is located on bovine chromosome 2, near quantitative trait loci (QTLs) for residual feed intake (RFI) (Martínez et al., 2010; Sherman et al., 2010), average daily gain (ADG) (Li et al., 2010), body weight (BW) (Casas et al., 2003), and REA (Allais et al., 2010).

The metabolic pathway in which this gene is involved is related to carbohydrate metabolism, specifically in the regulation of insulin gene expression (Malecki et al., 1999). Insulin is responsible for glucose reduction in the blood, and promotes the entry of glucose into the cells. It is essential for carbohydrate metabolism, protein synthesis, and lipid storage. Malecki et al. (1999) showed that mutations in human NEUROD1 are related to the development of diabetes mellitus type II.

Based on NEUROD1 function and previous data found in the literature, we evaluated this gene as a candidate for affecting production traits in Nelore cattle by a sequencing-based investigation of single nucleotide polymorphisms (SNPs), and by conducting association studies on BFT, REA, average body weight (ABW), and metabolic body weight (MBW).

\section{MATERIAL AND METHODS}

\section{Animals and phenotypic data}

The animals were handled and managed according to the Institutional Animal Care 
and Use Committee Guidelines, Brazilian Agricultural Research Corporation (EMBRAPA). A complete description of the genetic and experimental design is given in De Oliveira et al. (2014). In brief, 585 Nelore steers weighing $382.5 \mathrm{~kg}$ on average, the offspring of 34 sires, were used. Individual dry matter intake (DMI, $\mathrm{kg} / \mathrm{d}$ ) was obtained by measuring the difference between offer and refusal. Residual feed intake (RFI, $\mathrm{kg} / \mathrm{d}$ ) was computed as the residuals from a regression of DMI on mid-test $\mathrm{BW}^{0.75}$ and $\mathrm{ADG}$ using mixed models. Contemporary groups (CGs) were defined as feedlot location, year, animal origin, and pen type (individual or collective), and were considered fixed effects using the MIXED procedure in SAS (SAS Institute Inc., 2000). Phenotypes for BFT (mm) and REA $\left(\mathrm{cm}^{2}\right)$ were as described in Tizioto et al. (2012). Descriptive statistics for RFI, REA, BFT, ABW, and MBW are presented in Table 1. The number of animals $(\mathrm{N})$ used for each trait was different due to different data availability.

Table 1. Descriptive statistics for residual feed intake (RFI), ribeye area (REA), backfat thickness (BFT), average body weight $(\mathrm{ABW})$, and metabolic body weight (MBW) in Nelore steers.

\begin{tabular}{l|c|c}
\hline Trait & $\mathrm{N}$ & Means \pm SE \\
\hline RFI & 585 & $0.001 \pm 0.62$ \\
\hline REA & 394 & $59.98 \pm 7.55$ \\
\hline BFT & 394 & $6.42 \pm 2.33$ \\
\hline ABW & 396 & $386.5 \pm 0.34$ \\
\hline MBW & 396 & $87.2 \pm 0.14$ \\
\hline
\end{tabular}

\section{NEUROD1 sequencing}

DNA samples of 14 Nelore steers representing the extremes of BLUP (Best Linear Unbiased Prediction) values for RFI (seven high and seven low) were sequenced. The genetic analysis conducted to obtain the BLUP values was based on the following mathematical model (Tizioto et al., 2012):

$$
y=X \beta+Z a+e
$$

where $y$ is the vector of the response variable; $\beta$ is the vector of fixed effects of a CG consisting of year, pen type, and animal origin; $a$ is the vector of animal additive genetic effects [NID $(0, \mathrm{sa} 2)]$; and $\varepsilon$ is the vector of residual effects inherent to each observation [NID $(0, \mathrm{se} 2)]$. Animals were selected from the top 5\% highest and lowest values, taking into account that the animals were from families with different half-siblings.

Primers were designed for the complete sequencing of NEUROD1 (Table 2) based on the sequence (ENSBTAG00000001755) that is publicly available on the Ensembl database (http://www.ensembl.org/index.html). The sequencing reactions were performed according to the protocol adapted by Regitano and Coutinho (2001) using an ABI PRISM ${ }^{\circledR}$ BigDye $^{\circledR}$ Terminator v. 3.1 Cycle Sequencing kit (Applied Biosystems), and the fragments were sequenced on an ABI PRISM ${ }^{\circledR} 3100-$ Avant $^{\mathrm{TM}}$ sequencer (Applied Biosystems).

\section{SNP genotyping and association analysis}

Of the SNPs found by sequencing, one was associated with RFI according to a Fisher's exact test (Table 3). This SNP was further genotyped in 589 Nelore steers following 
the tetra-primer amplification refractory mutation system-polymerase chain reaction (ARMSPCR) method (Ye et al., 2001). Table 4 lists the primers used for SNP 1062G $>$ C genotyping by tetra-primer ARMS-PCR.

Table 2. Sequences, amplicon sizes, and annealing temperatures (AT) of primers for the complete sequencing of NEUROD1.

\begin{tabular}{|c|c|c|c|}
\hline Primer & \begin{tabular}{|l} 
Sequence 5'-3' \\
\end{tabular} & Amplicon size (bp) & AT $\left({ }^{\circ} \mathrm{C}\right)$ \\
\hline $1 \mathrm{~F}$ & СССТCTCCCCTGTTGAATGTAG & \multirow[t]{2}{*}{451} & \multirow[t]{2}{*}{59} \\
\hline $1 \mathrm{R}$ & CGACAGAGCCCAGATGTAGTTT & & \\
\hline $2 \mathrm{~F}$ & CTGAGACGCATGAAAGCCAAC & \multirow[t]{2}{*}{529} & \multirow[t]{2}{*}{59} \\
\hline $2 \mathrm{R}$ & GGACGGTTCGTGTTTGAAAG & & \\
\hline $3 \mathrm{~F}$ & CTGGAACCTTTCTTTGAGAGCC & \multirow[t]{2}{*}{436} & \multirow[t]{2}{*}{59} \\
\hline $3 \mathrm{R}$ & TTCTACCAAAGGCAGTAACGAC & & \\
\hline $4 \mathrm{~F}$ & GGCAGCCCTTTGAGTATTACTG & \multirow[t]{2}{*}{523} & \multirow[t]{2}{*}{59} \\
\hline $4 \mathrm{R}$ & GAGAAGAAAGAAGTGCTAAGGC & & \\
\hline $5 \mathrm{~F}$ & CTTGTTACCTTTCCCATGCTGA & \multirow[t]{2}{*}{466} & \multirow[t]{2}{*}{59} \\
\hline $5 \mathrm{R}$ & TCATGGGATGCAAAGGAGTA & & \\
\hline $6 \mathrm{~F}$ & GTTGTTGTGTTGCCTTAGCACTTC & \multirow[t]{2}{*}{902} & \multirow[t]{2}{*}{59} \\
\hline $6 \mathrm{R}$ & CTTCACAAACCTCACCCAACC & & \\
\hline
\end{tabular}

Table 3. Characteristics of single nucleotide polymorphisms (SNPs) identified in NEUROD1 in Nelore steers, with Fisher's exact test results between extremes of residual feed intake.

\begin{tabular}{|c|c|c|c|c|c|c|}
\hline \multicolumn{7}{|c|}{ NEURODI } \\
\hline $\mathrm{SNP}^{1}$ & Gene localization (bp) & Genic region $^{2}$ & Functional class & Sequence $^{3}$ & $P$ value & MAF \\
\hline $599 \mathrm{C}>\mathrm{G}$ & 599 & 5'UTR & nsSNPs & AAACCTAA(C/G)CATGACC & 0.3147 & 0.153 \\
\hline $1008 \mathrm{G}>\mathrm{A}$ & 1008 & coding region & nsSNPs & ACGCAGAA(G/A)CTGTCCA & 1.0000 & 0.143 \\
\hline $1062 \mathrm{G}>\mathrm{C}$ & 1062 & coding region & nsSNPs & GCTCTGTC(G/C)GAAATCT & $0.0600 *$ & 0.417 \\
\hline $1224 \mathrm{~T}>\mathrm{G}$ & 1224 & coding region & nsSNPs & CACCTGCC(T/G)ACCGCCA & 1.0000 & 0.369 \\
\hline $1743 \mathrm{~T}>\mathrm{C}$ & 1743 & 3'UTR & nsSNPs & AGGGCTGC(T/C)TTTGTAA & 1.0000 & 0.385 \\
\hline $2232 \mathrm{G}>\mathrm{T}$ & 2232 & 3'UTR & nsSNPs & AATTATTTT(G/T)TATAAATT & 0.3881 & 0.207 \\
\hline $2254 \mathrm{C}>\mathrm{T}$ & 2254 & 3'UTR & nsSNPs & TGCACTGTTT(C/T)TTTTTA & 0.5455 & 0.167 \\
\hline
\end{tabular}

${ }^{1}$ National Center for Biotechnology Information accession numbers: $599 \mathrm{C}>\mathrm{G}$ : 902923723 ; 1008G $>\mathrm{A}$ : 902923724; $1062 \mathrm{G}>\mathrm{C}$ : 902923725; 1224T $>\mathrm{G}: 902923726 ; 1743 \mathrm{~T}>\mathrm{C}: 902923727 ; 2232 \mathrm{G}>\mathrm{T}: 902923728 ; 2254 \mathrm{C}>\mathrm{T}$ : 902923729; ${ }^{2,3}$ Reference sequence deposited in Ensembl (ENSBTAG00000001755); ns, non-synonymous; *P < 0.10 ; MAF, minor allele frequency.

Table 4. Characteristics of primers used for single nucleotide polymorphism genotyping of NEUROD1 by tetra-primer amplification refractory mutation system-polymerase chain reaction.

\begin{tabular}{l|l|c}
\hline Primer & Sequence & bp \\
\hline Forward inner (allele C) & GCCAAAAACTACATCTGGGCTCTGACC & 172 \\
\hline Reverse inner (allele G) & GGCTTTTCCCTGAACGCAAGATTACC & 235 \\
\hline Forward outer (5'-3') & GGCCCCAAAAAGAAGAAGATGACGAA & 354 \\
\hline Reverse outer (5'-3') & GTCCTGGTTCTGCTCAGGCAGAAAAGT & 354 \\
\hline
\end{tabular}

Association analyses were performed by the restricted maximum likelihood method using the MIXED procedure in SAS with the following model (Tizioto et al., 2012):

$$
\mathrm{Y}_{\mathrm{ijkl}}=\mu+\mathrm{CG}_{\mathrm{i}}+\mathrm{M}_{\mathrm{j}}+\mathrm{S}_{\mathrm{k}}+\mathrm{b}_{1}\left(\mathrm{~A}_{\mathrm{ijkl}}-\mathrm{a}\right)+\mathrm{e}_{\mathrm{ijk} \mathrm{l}}
$$

where $Y_{i j k l}$ is the observation of the 1 st individual of age $A$, sibling of the $k$ th sire, of the $j$ th 
genotype for the marker belonging to the $i$ th $C G ; \mu$ is the overall mean; $C G_{i}$ is the fixed effect of the $i$ th CG; $M_{i}$ is the fixed effect of the $j$ th genotype for the marker; $S k$ is the random effect associated with the $k$ th sire $\left[\sim \mathrm{N}\left(0, \mathrm{~s}_{\mathrm{t}}^{2}\right)\right] ; b$ is the regression coefficient associated with the animal's age; $A_{i j k l}$ is the animal's age on the date of measurement, and $a$ is the mean age at measurement; and $e_{i j k l}$ is the random error associated with each observation $\left[\sim \mathrm{N}\left(0, \mathrm{~s}_{\mathrm{e}}^{2}\right)\right]$. The CG included the effects of birth and feedlot place, month of birth, breeding season, and slaughter date. The MIXED procedure in SAS (proc mixed) was used to test the additivedominance model.

\section{RESULTS}

By sequencing 14 animals with extreme RFI BLUP values, seven novel SNPs in NEUROD1 were identified (Table 3). Minor allele frequencies of the SNPs identified in the extreme animals ranged from 0.14 to 0.41 . Four SNPs were found in regulatory and coding regions, one in the 5' untranslated region (UTR), and three in the 3'UTR.

In order to evaluate the effect of NEURODI on RFI, the genotype frequencies of the SNPs were compared between groups of steers with extreme RFI phenotypes using Fisher's exact test. SNP 1062G $>$ C (Table 3), which substitutes cytosine for guanine and is located in a coding region, was non-significantly associated with RFI $(\mathrm{P}=0.060)$; therefore, $\mathrm{SNP} 1062 \mathrm{G}>\mathrm{C}$ was chosen to evaluate the entire population.

Allelic and genotypic frequencies for NEUROD1 in the Nelore population are presented in Table 5 . When evaluated in the entire population, a significant association between SNP $1062 \mathrm{G}>\mathrm{C}$ and RFI was not observed $(\mathrm{P}=0.7186)$.

Table 5. Allele and genotype frequency of SNP $1062 \mathrm{G}>\mathrm{C}$ in NEUROD1 in a Nelore population.

\begin{tabular}{l|c|c|c|c|c}
\hline \multirow{2}{*}{ Gene } & \multicolumn{3}{|c|}{ Frequency (\%) } & \multicolumn{3}{c}{ Genotypic } \\
\cline { 2 - 6 } & \multicolumn{2}{|c|}{ Allelic } & CC & CG & GG \\
\hline NEUROD1 & C & G & 41.7 & 33.33 & 25.00 \\
\hline $\mathrm{N}=585$ & 58 & 42 & &
\end{tabular}

The first approach adopted was to investigate the effects of SNP 1062G $>$ C on RFI based on information from previous studies (Barendse et al., 2007). However, based on the physiological and metabolic functions of NEUROD1 and its location in a region described for other production traits, we evaluated the effects of NEUROD1 on other production traits (BFT, REA, ABW, and MBW).

A significant dominance deviation effect on $\mathrm{BFT}(\mathrm{P}=0.0009)$ and significant additive effects on ABW ( $\mathrm{P}=0.0249)$ and MBW $(\mathrm{P}=0.0267)$ were found (Table 6$)$. The estimated allele substitution effects of the SNP were $-1.59 \mathrm{~kg}$ and $-0.93 \mathrm{~kg}^{0.75}$ for ABW and MBW, respectively; therefore, the $\mathrm{C}$ allele decreased both $\mathrm{ABW}$ and $\mathrm{MBW}$ in this population. This polymorphism accounted for 7.78 and $0.21 \%$ of the total additive variance for ABW and MBW, respectively, and 9.98 and $0.27 \%$ of the total genetic variance for them, respectively. Dominance deviations were not significant for these traits. We did not find a significant association between this SNP and REA $(\mathrm{P}=0.2007)$. 


\begin{tabular}{|c|c|c|c|c|c|}
\hline & \multirow[t]{2}{*}{$\mathrm{N}$} & \multicolumn{4}{|c|}{ SNP $1062 \mathrm{G}>\mathrm{C}$} \\
\hline & & Genotype & Least square means $\pm \mathrm{SE}$ & Additive effect & Dominance deviation effect \\
\hline \multirow[t]{3}{*}{$\operatorname{BFT}\left(\mathrm{cm}^{2}\right)$} & \multirow[t]{3}{*}{396} & $\mathrm{CC}$ & $5.75 \pm 0.21$ & \multirow[t]{3}{*}{ ns } & \multirow[t]{3}{*}{1.35} \\
\hline & & CG & $6.51 \pm 0.14$ & & \\
\hline & & GG & $5.91 \pm 0.51$ & & \\
\hline \multirow[t]{3}{*}{ ABW $(\mathrm{kg})$} & \multirow[t]{3}{*}{396} & $\mathrm{CC}$ & $388.57 \pm 4.6$ & \multirow[t]{3}{*}{-1.59} & \multirow[t]{3}{*}{$\mathrm{ns}$} \\
\hline & & CG & $397.33 \pm 3.9$ & & \\
\hline & & GG & $400.07 \pm 4.5$ & & \\
\hline \multirow[t]{3}{*}{ MBW $\left(\mathrm{kg}^{0.75}\right)$} & \multirow[t]{3}{*}{396} & $\mathrm{CC}$ & $87.40 \pm 0.79$ & \multirow[t]{3}{*}{-0.93} & \multirow[t]{3}{*}{ ns } \\
\hline & & CG & $88.87 \pm 0.66$ & & \\
\hline & & GG & $89.32 \pm 0.77$ & & \\
\hline
\end{tabular}

$\mathrm{BFT}=$ backfat thickness; $\mathrm{ABW}=$ average body weight; $\mathrm{MBW}=$ metabolic body weight; $\mathrm{N}=$ number of observations; $\mathrm{ns}=$ not significant $(\mathrm{P} \geq 0.05)$

\section{DISCUSSION}

Barendse et al. (2007) found a different polymorphism in NEUROD1 associated with RFI in a Bos taurus population, which was not found in the Nelore population studied here. Discrepancies in allele frequency and the extent of linkage disequilibrium could result in different marker effects being detected in different breeds. Conflicting results for candidate genes are usually linked to genetic differences between populations or subspecies of cattle, and can be attributed to the environmental conditions, management, and diet to which each population is exposed (Rincker et al., 2006).

NEUROD1 is a transcription factor that regulates, as an activator, insulin gene expression by binding to a critical E-box motif on the insulin gene promoter (Malecki et al., 1999). Insulin is a neuromodulator in the nervous system, and is considered a hormone sensor of peripheral metabolism. This protein attaches to specific brain receptors, and controls the most important areas related to consumption and energy metabolism in the brain (Ingvartsen and Andersen, 2000). The role of insulin in regulating feed intake and body weight in cattle has been reported previously (Richardson and Herd, 2002; Rolf et al., 2012; Karisa et al., 2014).

The effect of NEUROD1 genotypes on BFT observed in this study may be attributed to the function of this gene in metabolism and lipid storage by modulating insulin secretion. The effect of insulin on the metabolism of fatty acids is opposite to that of the hormones glucagon and adrenaline. Insulin secretion in response to high blood glucose levels stimulates lipogenesis (Brockman, 1983).

Although SNP $1062 \mathrm{G}>\mathrm{C}$ does not result in amino acid substitution, the effects observed may be caused by a variety of genetic mechanisms, e.g., SNP 1062C $>$ G may be in linkage disequilibrium with another SNP in regulatory regions, or with a gene that is related to lipid metabolism.

NEUROD1 is mapped to bovine chromosome 2 near QTLs for RFI, ADG, BW, and REA (Casas et al., 2003; Allais et al., 2010; Li et al., 2010; Martínez et al., 2010; Sherman et al., 2010). Seven candidate genes, including bridging integrator 1 (BIN1), asparagine synthetase domain-containing protein 1 (ASNSD1), and aldehyde oxidase $(A O X 1)$ are associated with RFI on bovine chromosome 2 (Karisa et al., 2013), near to SNPs (599C $>\mathrm{G}$, $1008 \mathrm{G}>\mathrm{A}$, and $1743 \mathrm{~T}>\mathrm{C}$ ) found in NEUROD1. The fact that a significant association between this polymorphism and RFI has not been found suggests that using this marker information in selecting for BFT, ABW, and MBW would not affect RFI. 
Several studies have identified genes that are associated with production traits, but their biological mechanisms are not well understood because individual gene effects should be considered in the context of a polygenic background. The knowledge obtained from candidate genes helps to explain the biological mechanisms underlying variation in target traits; however, it is not enough to identify the contribution of a single genetic variant, because most traits are influenced by many genes.

Based on our results, NEUROD1 is a candidate gene for BFT, ABW, and MBW in this population of Nelore cattle. However, the validation of this marker in different populations of cattle is necessary before it can be implemented in marker-assisted selection. Once confirmed, inclusion of NEUROD1-associated SNPs in dense panels may improve the accuracy of genomic selection for different production traits, as this SNP is not currently represented on commercially available SNP chips.

\section{Conflicts of interest}

The authors declare no conflict of interest.

\section{ACKNOWLEDGMENTS}

We thank Farm Novo Horizonte for the animals, Andrea Souza and Amalia S. Chaves for conducting the experiments, CNPq for financial assistance, and CAPES for Priscila Silva Neubern de Oliveira's scholarship.

\section{REFERENCES}

Allais S, Levéziel H, Payet-Duprat N, Hocquette JF, et al. (2010). The two mutations, Q204X and nt821, of the myostatin gene affect carcass and meat quality in young heterozygous bulls of French beef breeds. J. Anim. Sci. 88: 446-454. http://dx.doi.org/10.2527/jas.2009-2385

Barendse W, Reverter A, Bunch RJ, Harrison BE, et al. (2007). A validated whole-genome association study of efficient food conversion in cattle. Genetics 176: 1893-1905. http://dx.doi.org/10.1534/genetics.107.072637

Basarab JA, Price MA, Aalhus JL, Okine EK, et al. (2003). Residual feed intake and body composition in young growing cattle. Can. J. Anim. Sci. 83: 189-204. http://dx.doi.org/10.4141/A02-065

Brockman, R. P (1983). Effects of insulin and glucose on the production and utilization of glucose in sheep. Comp. Biochem. Physiol. 74: 681.

Casas E, Shackelford SD, Keele JW, Koohmaraie M, et al. (2003). Detection of quantitative trait loci for growth and carcass composition in cattle. J. Anim. Sci. 81: 2976-2983.

De Oliveira PSN, Cesar ASM, Do Nascimento ML, Chaves AS, et al. (2014). Identification of genomic regions associated with feed efficiency in Nelore cattle. BMC Genet. 15: 100.

Ingvartsen KL and Andersen JB (2000). Integration of metabolism and intake regulation: a review focusing on periparturient animals. J. Dairy Sci. 83: 1573-1597. http://dx.doi.org/10.3168/jds.S0022-0302(00)75029-6

Karisa B, Moore S and Plastow G (2014). Analysis of biological networks and biological pathways associated with residual feed intake in beef cattle. Anim. Sci. J. 85: 374-387. http://dx.doi.org/10.1111/asj.12159

Karisa BK, Thomson J, Wang Z, Stothard P, et al. (2013). Candidate genes and single nucleotide polymorphisms associated with variation in residual feed intake in beef cattle. J. Anim. Sci. 91: 3502-3513. http://dx.doi.org/10.2527/ jas.2012-6170

Li F, Chen H, Lei CZ, Ren G, et al. (2010). Novel SNPs of the bovine GADl/gad67 gene and their association with growth traits in three native Chinese cattle breeds. Mol. Biol. Rep. 37: 501-505. http://dx.doi.org/10.1007/s11033-009-9699-8

Malecki MT, Jhala US, Antonellis A, Fields L, et al. (1999). Mutations in NEUROD1 are associated with the development of type 2 diabetes mellitus. Nat. Genet. 23: 323-328. http://dx.doi.org/10.1038/15500

Martínez A, Aldai N, Celaya R and Osoro K (2010). Effect of breed body size and the muscular hypertrophy gene in 
the production and carcass traits of concentrate-finished yearling bulls. J. Anim. Sci. 88: 1229-1239. http://dx.doi. org/10.2527/jas.2009-2025

Regitano LCA and Coutinho LL (2001). Biologia molecular aplicada à produção animal. Embrapa-Informação Tecnológica, 215p.

Richardson EC and Herd RM (2002). Biological basis for variation in residual feed intake in beef cattle. Synthesis of results following divergent selection. Aust. J. Exp. Agric. 44: 431-440. http://dx.doi.org/10.1071/EA02221

Rincker CB, Pyatt NA, Berger LL and Faulkner DB (2006). Relationship among GeneSTAR marbling marker, intramuscular fat deposition, and expected progeny differences in early weaned Simmental steers. J. Anim. Sci. 84: 686-693.

Rolf MM, Taylor JF, Schnabel RD, McKay SD, et al. (2012). Genome-wide association analysis for feed efficiency in Angus cattle. Anim. Genet. 43: 367-374. http://dx.doi.org/10.1111/j.1365-2052.2011.02273.x

SAS Institute Inc (2000). Procedures guide. 8th edn. Cary, NC, USA.

Sherman EL, Nkrumah JD and Moore SS (2010). Whole genome SNP associations with feed intake and feed efficiency in beef cattle. J. Anim. Sci. 88: 16-22. http://dx.doi.org/10.2527/jas.2008-1759

Tizioto PC, Meirelles SL, Veneroni GB, Tullio RR, et al. (2012). A SNP in ASAP1 gene is associated with meat quality and production traits in Nelore breed. Meat Sci. 92: 855-857. http://dx.doi.org/10.1016/j.meatsci.2012.05.018

Ye S, Dhillon S, Ke X, Collins AR, et al. (2001). An efficient procedure for genotyping single nucleotide polymorphisms. Nucleic Acids Res. 29: E88. http://dx.doi.org/10.1093/nar/29.17.e88 